\title{
Stable serum resistance of Neisseria gonorrhoeae as an epidemiological marker
}

\author{
A LAVITOLA,* P M V MARTIN,* Y PEAN, + M GUIBOURDENCHE,* \\ AND J Y RIOU* \\ From the *Laboratoire des Neisseria, Unité d'Ecologie Bactérienne, Institut Pasteur, and the †Hôpital de \\ la Cité Universitaire, Paris, France
}

SUMMARY Using a simple and rapid microassay, we tested 100 strains of Neisseria gonorrhoeae isolated from 81 patients ( 41 men and 40 women) for their sensitivity to killing by normal human serum (NHS). The reproducibility of the test was good when the bactericidal end points were taken as the dilution of fresh NHS that killed more than $95 \%$ of the test organisms. The bactericidal end points of strains isolated either from different anatomical sites or from sexual partners correlated well with the levels of sensitivity to serum of corresponding isolates, as well as with auxotypes. When the strains were not highly resistant to killing by NHS, this marker gave a precise definition of each strain and permitted the differentation of isolates belonging to common auxotypes.

\section{Introduction}

Neisseria gonorrhoeae is resistant to the bactericidal action of normal human serum when examined in vivo. ${ }^{1}$ After one or more subcultures on a laboratory medium, however, some strains retain their serum resistance while others become sensitive to killing by normal human serum. The level of sensitivity to serum after subculturing is taken as stable. Schneider and Griffiss ${ }^{2}$ recently described a microassay for the assessment of bactericidal activity of normal human serum against gonococcal strains. This method permitted the testing of large numbers of different strains, based on their ability to reduce triphenyl tetrazolium chloride (TTC) as a measure of their viability. We used this procedure to investigate the level of sensitivity to killing by normal human serum as a posssible marker for epidemiological purposes. There is a need for a number of markers for $N$ gonorrhoeae as the epidemiological value of auxotyping, ${ }^{3}$ the most commonly used marker system, is limited because only one or two auxotypes are predominant. The geographical distribution of auxotypes of $N$ gonorrhoeae, however, is of great help in the understanding of the epidemiology of gonorrhoea. In this preliminary study, stable sensitivity to serum was used as a second marker and was compared with auxotyping. The stability of sensitivity to serum

Address for reprints: Dr P M V Martin, Unité d'Ecologie Bactérienne, Institut Pasteur, 28 rue du Dr Roux, 75015 Paris, France

Accepted for publication 6 January 1984 through natural transmission (in vivo) was assessed by comparing strains isolated from sexual partners and from different anatomical sites. These markers will later be used with others (such as serotypes) for studies on strains isolated from the same patients in the course of repeat gonococcal infections.

\section{Materials and methods}

\section{STRAINS}

One hundred strains of $N$ gonorrhoeae were isolated from 81 patients (41 men, 40 women) in 1981-82 at the International Student Hospital in Paris. Twenty six of these strains were grown from different anatomical sites in 10 patients, and 35 were isolated from people who were sexual partners. Gonococci were identified by Gram stain microscopy, oxidase test reaction, and sugar oxidation patterns (Galerie Neisseria, Institut Pasteur Production, IPP). One reference strain, BS4 (agar), ${ }^{4}$ was also used to standardise the bactericidal activity of the pool of fresh NHS for comparison in further studies. Before they were tested all strains were subcultured three times or more on "Gono-Meningo" medium (IPP) containing supplement G (IPP) at $37^{\circ} \mathrm{C}$ for 20 hours in candle extinction jars.

NORMAL HUMAN SERUM

A pool of serum was obtained from seven volunteers with no history of gonorrhoea. The serum was processed aseptically at $4^{\circ} \mathrm{C}$ to preserve complement, and was distributed into vials in small volumes. Half of them were heated at $56^{\circ} \mathrm{C}$ for 45 minutes and then 
kept at $-20^{\circ} \mathrm{C}$ (heated human serum), and the rest were frozen at $-70^{\circ} \mathrm{C}$ (fresh human serum).

\section{BACTERICIDAL MICROASSAY}

We used a test recently described by Schneider and Griffiss, ${ }^{2}$ but with the following slight modifications: a chemically defined medium ${ }^{5}$ was used instead of Gey's balanced salts solution for dilutions of serum and suspensions of organisms, and triphenyl tetrazolium chloride (TTC) (Sigma) was used at a concentration of $0.005 \%$ instead of $0.0025 \%$. Briefly, serial twofold dilutions $(0.025 \mathrm{ml})$ of either fresh or heated human serum were made in duplicate in microtitre plates. The same volume of chemically defined medium (with $0.2 \%$ bovine serum albumin) containing 200-400 organisms was added. The plates were incubated for 45 minutes at $37^{\circ} \mathrm{C}$, and $0.025 \mathrm{ml}$ of TTC was added, the plates were shaken, and $0.11 \mathrm{ml}$ of "Gono-Meningo" agar (maintained at $52^{\circ} \mathrm{C}$ ) containing supplement $\mathrm{G}$ was added. After 24 hours' incubation at $37^{\circ} \mathrm{C}$ microcolonies were counted under a dissecting microscope, and sensitivity to serum was calculated as the percentage of microcolonies in fresh human serum compared with the number in heated human serum. Each strain was tested in duplicate in different experiments.

\section{AUXOTYPING}

Auxotyping was performed in our laboratory using the method described by Catlin. ${ }^{3}$ One hundred strains were chosen to provide a good distribution between isolates from male and female patients, isolates from different anatomical sites, and isolates from sexual partners. Of the 100 strains, 46 were non-requiring (auxotype zero), 28 required proline $\left(\mathrm{Pro}^{-}\right)$, six arginine $\left(\mathrm{Arg}^{-}\right)$, five arginine, hypoxanthine, and uracil (Arg-Hyp-Ura ${ }^{-}$), 12 had diverse multiple auxotypes (five requiring proline and arginine (Pro- $\left.\mathrm{Arg}^{-}\right)$, three proline, arginine, and uracil (Pro-Arg-Ura- ${ }^{-}$, one proline and methionine (Pro-Met ${ }^{-}$), one methionine and arginine (Met$\left.\mathrm{Arg}^{-}\right)$, one arginine and uracil (Arg-Ura $\left.{ }^{-}\right)$, and one proline, methionine, and arginine (Pro-Met-Arg $\left.{ }^{-}\right)$), and two were non-auxotypable.

\section{Results}

REPRODUCIBILITY OF THE ASSAY

TTC (triphenyl tetrazolium chloride) is reduced by growing bacteria and imparts a red colour to the colonies after 24 to 48 hours. About $15 \%$ of the strains were not coloured by TCC, however, but the reading remained consistent. We found that a concentration of $0.005 \%$ of TTC gave a better colouration than $0.0025 \%,{ }^{2}$ although the growth of nine out of 100 strains was inhibited by this concentration of TTC.
Although Schneider and Griffiss recommended 95\% killing as the bactericidal end point, ${ }^{2}$ in most investigations of gonococcal sensitivity to serum the bactericidal end point has been taken as the greatest dilution that killed $50 \%$ of the bacteria inoculated. Comparing 50\% and $95 \%$ killing end points in four experiments, we found a difference of one dilution in 22 and 15 cases respectively, and a difference of more than one dilution in three and no cases respectively. Thus the reproducibility of the microassay was better when the bactericidal end point for each strain was taken as the greatest dilution that killed $95 \%$ of the bacteria. Our results are expressed only on this basis.

The reference strain BS4 (agar) was sensitive to a $1 / 64$ dilution of fresh human serum used in this study. Of 91 strains that were not inhibited by TTC, 33 were killed ( $95 \%$ end point) by a dilution of fresh human serum greater than $1 / 2$. Because of this relative rarity $(36 \%)$, the level of sensitivity to serum of these strains gave a more precise definition of each strain than when they appeared to be highly resistant to killing by fresh human serum.

\section{COMPARISON OF SENSITIVITIES TO SERUM BETWEEN SEXES AND AUXOTYPES}

Of the 46 zero auxotype strains, 18 were isolated from men and 28 from women. The levels of sensitivity to serum did not show significant differences $\left(\chi^{2} ; p>0 \cdot 05\right)$. When strains of different auxotypes were compared, no significant differences $(p>0.05)$ were found in the levels of sensitivity to serum. The five strains requiring arginine, hypoxanthine, and uracil were highly resistant to serum, although they were not isolated from patients with disseminated infections. ${ }^{4}$

Despite the commonly accepted observation that gonococci usually persist longer in the urogenital tracts of women than of men, the similarity in levels of sensitivity to serum of strains isolated from the urogenital tracts of men and women indicated that the level of sensitivity to serum of a strain was a stable characteristic of isolates from the urogenital tract.

COMPARISON OF ISOLATES FROM DIFFERENT ANATOMICAL SITES AND FROM CORRESPONDING SEXUAL PARTNERS

The stability of an epidemiological marker during the course of an infection is an inherent requirement for its reliability. On the basis of these markers we compared sets of strains isolated from different anatomical sites (urethra, vagina, cervix, anus, and throat) from each of 10 women. Table I shows that in cases 1,2 , and 7 strains isolated from the urethra, vagina, or cervix, had the same auxotype and the same level of sensitivity to serum, while in case 3 
TABLE 1 End points of sensitivity to serum* of 26 strains of Neisseria gonorrhoeae isolated from different anatomical sites in 10 female patients

\begin{tabular}{|c|c|c|c|c|c|c|c|c|c|c|}
\hline \multirow{3}{*}{$\frac{\text { Case No }}{1}$} & \multirow{3}{*}{$\begin{array}{l}\text { Auxotype } \\
\text { Non-auxotypable }\end{array}$} & \multicolumn{6}{|c|}{ Sensitivity end points* of strains isolated from: } & & \multirow{3}{*}{ Throat } \\
\hline & & \multicolumn{2}{|c|}{ Urethra } & \multicolumn{2}{|c|}{ Vagina } & \multicolumn{2}{|l|}{ Cervix } & \multicolumn{2}{|c|}{ Anus } & \\
\hline & & & & $1 / 2$ & $1 / 4$ & $1 / 4$ & $1 / 4$ & & . & \\
\hline 2 & Zero & $1 / 8$ & $1 / 8$ & $1 / 8$ & $1 / 16$ & & & & & \\
\hline $3+$ & $\begin{array}{l}\text { Pro- } \\
\text { Pro-Meth- }\end{array}$ & $<1 / 2$ & $<1 / 2$ & $1 / 8$ & $1 / 16$ & & & & & \\
\hline 4 & Pro-Arg-Ura & $1 / 8$ & $1 / 16$ & & & & & $1 / 8$ & $1 / 16$ & \\
\hline 5 & Pro $^{-}$ & $<1 / 2$ & $<1 / 2$ & $<1 / 2$ & $<1 / 2$ & $<1 / 2$ & $<1 / 2$ & & & \\
\hline 6 & Zero & $<1 / 2$ & $<1 / 2$ & $<1 / 2$ & $<1 / 2$ & $<1 / 2$ & $<1 / 2$ & & & \\
\hline 7 & Pro $^{-}$ & $1 / 4$ & $1 / 4$ & $1 / 4$ & $1 / 4$ & $1 / 4$ & $1 / 8$ & & & . \\
\hline 8 & $\mathrm{Arg}^{-}$ & & & $1 / 8$ & Inh $\neq$ & & & $1 / 8$ & Inh $\neq$ & 1/8 Inh $\neq$ \\
\hline $9+$ & $\begin{array}{l}\text { Zero } \\
\text { Pro- }\end{array}$ & $<1 / 2$ & $<1 / 2$ & $<1 / 2$ & $<1 / 2$ & $<1 / 2$ & $<1 / 2$ & & & \\
\hline 10 & Pro- & $<1 / 2$ & $<1 / 2$ & $<1 / 2$ & $<1 / 2$ & $<1 / 2$ & $<1 / 2$ & & & \\
\hline
\end{tabular}

* The greatest dilution of fresh human serum that killed $\geqslant 95 \%$ of the strain.

Each strain was tested in duplicate, and each figure is the mean of two tests.

†Two different strains were isolated from the same patient.

F Growth was inhibited by triphenyl tetrazolium chloride.

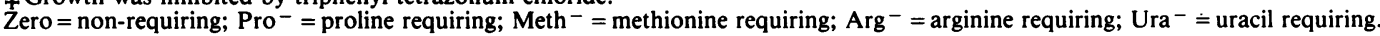

strains isolated from the urethra and cervix could be differentiated by their auxotype as well as by their levels of sensitivity to serum. In case 9 , however, both strains (non-requiring from the urethra and vagina, and proline requiring from the cervix) were highly resistant and could not be differentiated. Thus when the strains were not highly resistant their sensitivity to serum provided a precise measure which permited a good definition of the strain.

Table II shows the sensitivity to serum of strains isolated from men and of the corresponding strains from their sexual partners. A good relation was seen

TABLE II End points of sensitivity to serum* of strains of Neisseria gonorrhoeae isolated from sexual partners

\begin{tabular}{|c|c|c|c|c|c|c|c|}
\hline \multirow{2}{*}{$\begin{array}{l}\begin{array}{l}\text { Case No } \\
\text { (men) }\end{array} \\
1\end{array}$} & \multirow{2}{*}{$\begin{array}{l}\text { Auxotype } \\
\text { Zero }\end{array}$} & \multicolumn{2}{|c|}{$\begin{array}{l}\text { Sensitivity } \\
\text { end points* }\end{array}$} & \multirow{2}{*}{ 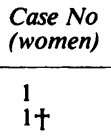 } & \multirow{2}{*}{$\begin{array}{l}\text { Auxotype } \\
\text { Zero } \\
\text { Zero }\end{array}$} & \multicolumn{2}{|c|}{$\begin{array}{l}\text { Sensitivity } \\
\text { end points* }\end{array}$} \\
\hline & & $1 / 32$ & $1 / 32$ & & & $\begin{array}{l}1 / 64 \\
1 / 64\end{array}$ & $\begin{array}{l}1 / 64 \\
1 / 32\end{array}$ \\
\hline 2 & Zero & $<1 / 2$ & $<1 / 2$ & 2 & Zero & $<1 / 2$ & $<1 / 2$ \\
\hline 3 & Zero & $<1 / 2$ & $<1 / 2$ & 3 & Zero & $<1 / 2$ & $<1 / 2$ \\
\hline 4 & Zero & $<1 / 2$ & $<1 / 2$ & 4 & Zero & $<1 / 2$ & $<1 / 2$ \\
\hline 5 & Zero & $1 / 8$ & $1 / 8$ & 5 & Zero & $1 / 8$ & $1 / 8$ \\
\hline 6 & Pro $^{-}$ & $1 / 128$ & $1 / 64$ & 6 & Pro $^{-}$ & $1 / 64$ & $1 / 64$ \\
\hline 7 & Pro $^{-}$ & $1 / 8$ & $1 / 8$ & 7 & Pro- & $1 / 16$ & $1 / 8$ \\
\hline 8 & Pro $^{-}$ & $1 / 2$ & $1 / 2$ & 8 & $\begin{array}{l}\text { Pro- (urethra) } \\
\text { Pro- (vagina) } \\
\text { Pro- (cervix) }\end{array}$ & $\begin{array}{l}1 / 4 \\
1 / 4 \\
1 / 4\end{array}$ & $\begin{array}{l}1 / 4 \\
1 / 4 \\
1 / 8\end{array}$ \\
\hline 9 & Pro $^{-}$ & $<1 / 2$ & $1 / 2$ & 9 & $\begin{array}{l}\text { Pro- (urethra) }^{-} \\
\text {Pro- (vagina) } \\
\text { Pro- (cervix) }^{-}\end{array}$ & $\begin{array}{l}<1 / 2 \\
<1 / 2 \\
<1 / 2\end{array}$ & $\begin{array}{l}<1 / 2 \\
<1 / 2 \\
<1 / 2\end{array}$ \\
\hline 10 & Pro $^{-}$ & $1 / 2$ & $<1 / 2$ & 10 & Pro $^{-}$ & $<1 / 2$ & $<1 / 2$ \\
\hline 11 & Pro $^{-}$ & $<1 / 2$ & $<1 / 2$ & 11 & $\begin{array}{l}\text { Pro-Arg- } \\
\text { Not tested }\end{array}$ & $\begin{array}{l}\text { Inh } \neq \\
\text { Inh } \neq\end{array}$ & $\begin{array}{l}\text { Inhł } \\
\text { Inhł }\end{array}$ \\
\hline 12 & Arg-Hyp-Ura- & $1 / 2$ & $<1 / 2$ & 12 & Arg-Hyp-Ura- & $1 / 2$ & $<1 / 2$ \\
\hline 13 & Arg-Hyp-Ura- & $<1 / 2$ & $<1 / 2$ & 13 & Arg-Hyp-Ura- & $<1 / 2$ & $<1 / 2$ \\
\hline 14 & Pro-Arg-Ura & $1 / 8$ & $1 / 8$ & 14 & $\begin{array}{l}\text { Pro-Arg-Ura- (urethra) } \\
\text { Pro-Arg-Ura- (anus) }\end{array}$ & $\begin{array}{l}1 / 8 \\
1 / 8\end{array}$ & $\begin{array}{l}1 / 8 \\
1 / 8\end{array}$ \\
\hline
\end{tabular}

* The greatest dilution of fresh human serum that killed $\geqslant 95 \%$ of the strain.

Each strain was tested in duplicate, and each figure is the mean of two tests.

+ Second sexual partner of the corresponding man.

$\neq$ Growth was inhibited by triphenyl tetrazolium chloride.

Zero = non-requiring; Pro ${ }^{-}=$proline requiring; Arg $^{-}=$arginine requiring; $\mathrm{Hyp}^{-}=$hypoxanthine requiring; Ura $^{-}=$uracil requiring. $^{-}$ 
between auxotype characteristics and sensitivity to serum. In cases $1,5,6,7$, and 8 the auxotypes were either non-requiring (zero) or proline requiring $\left(\right.$ Pro $\left.^{-}\right)$, which are both common auxotypes in France. ${ }^{6}$ The level of sensitivity to serum strongly supported the auxotype pattern. In case 1 , for example, the isolate from the man could not have been identified with both the strains cultured from his two female sexual partners on the basis of the auxotype (zero) only, while in case 14 the rare proline, arginine, and uracil requiring (Pro-Arg$\mathrm{Ura}^{-}$) auxotype of the isolates from both partners was sufficient to confirm their identity.

\section{Discussion}

The use of this simple microassay, which measures the sensitivity to serum of $N$ gonorrhoeae, permits large numbers of tests to be performed in a minimum of time and with good reproducibility. No significant difference in the level of sensitivity to serum was seen between strains isolated from men and women who were not sexual partners or between different auxotypes. The good correlation between the level of sensitivity to serum and the auxotypes of strains from several anatomical sites in the same person shows the possibility of using this variable as an epidemiological tool. Comparing 35 isolates from 14 sexual partners, there was only one case (no 8, table II) in which the isolate from the cervix had a sensitivity to serum differing from that of the isolate from the corresponding man by more than one dilution of serum. In such cases, when both strains belong to the same auxotype, it would be necessary to increase the number of tests to confirm or deny the similarity of strains. The association of these two markers enhances the value of each, particularly in cases where strains belong to common auxotypes. When a strain is highly resistant to serum, however, (table II, cases 2, 3, and 4) this marker seems to be less important. Conversely, when strains are sensitive to killing by human serum, the measure of sensitivity to serum provides a precise figure that can easily be compared with other variables and thus be useful in the identification of the similarities between strains.

This simple bactericidal assay should be helpful in the differentiation of isolates with the same common auxotype. The measure of sensitivity to serum will be used in the future as an epidemiological tool for studies on repeated gonococcal infections.

\section{References}

1. Ward ME, Watt PJ, Glynn AA. Gonococci in urethral exudate possess a virulence factor lost on subculture. Nature 1970; 227:382-4.

2. Schneider H, Griffiss JMcL. A bactericidal microassay for testing serum sensitivity of Neisseria gonorrhoeae. J Immunol Methods 1982; 54: 101-5.

3. Catlin BW. Nutritional profiles of Neisseria gonorrhoeae, Neisseria meningitidis and Neisseria lactamica in chemically defined media and the use of growth requirements for gonococcal typing. $J$ Infect Dis $1973 ; 128: 178-94$.

4. Martin PMV, Guibourdenche M, Riou JY. Resistance to killing by serum, auxotypes and disseminated gonococcal infections. N Engl J Med 1982;307: 1214.

5. Veale DR, Penn CW, Smith $\mathrm{H}$. Factors affecting the induction of phenotypically determined serum resistance of Neisseria gonorrhoeae grown in media containing serum or its diffusible components. J Gen Microbiol 1981; 122:235-45.

6. Riou JY, Martin PMV, Guibourdenche M. Surveillance épidémiologique des gonocoques producteurs de bétalactamase: auxotypage de $\mathbf{8 3}$ souches isolées en France. Nouv Presse Med (in press). 